\title{
Multiscale Mechanistic Insights of Shaped Catalyst Body Formulations and Their Impact on Catalytic Properties
}

Gareth T. Whiting, ${ }^{*}{ }^{\dagger}$ Sang-Ho Chung, ${ }^{\dagger}$ Dusan Stosic, ${ }^{\S}$ Abhishek Dutta Chowdhury, ${ }^{\dagger}$ Lars I. van der Wal, ${ }^{\dagger}$ Donglong Fu, ${ }^{\dagger}$ Jovana Zecevic, ${ }^{\dagger}$ Arnaud Travert, ${ }^{\S}$ Klaartje Houben, ${ }^{\ddagger}$ Marc Baldus, and Bert M. Weckhuysen*, ${ }^{*}$

${ }^{\dagger}$ Inorganic Chemistry and Catalysis Group, Debye Institute for Nanomaterials Science, Utrecht University, Universiteitsweg 99, Utrecht 3584 CG, The Netherlands

${ }^{\ddagger}$ NMR Spectroscopy, Bijvoet Center for Biomolecular Research, Utrecht University, Padualaan 8, Utrecht $3584 \mathrm{CH}$, The

Netherlands

${ }^{\S}$ ENSICAEN, UNICAEN, CNRS, Laboratoire Catalyse et Spectrochimie, Normandie University, Caen 14000, France

\author{
Supporting Information
}

ABSTRACT: Zeolite-based catalysts are globally employed in many industrial processes, such as in crude-oil refining and in the production of bulk chemicals. However, to be implemented in industrial reactors efficiently, zeolite powders are required to be shaped in catalyst bodies. Scale-up of zeolite catalysts into such forms comes with side effects to its overall physicochemical properties and to those of its constituting components. Although fundamental research into "technical" solid catalysts is scarce, binder effects have been reported to significantly impact their catalytic properties and lifetime. Given the large number of additional (in)organic components added in the formulation, it is somehow surprising to see that there is a distinct lack of

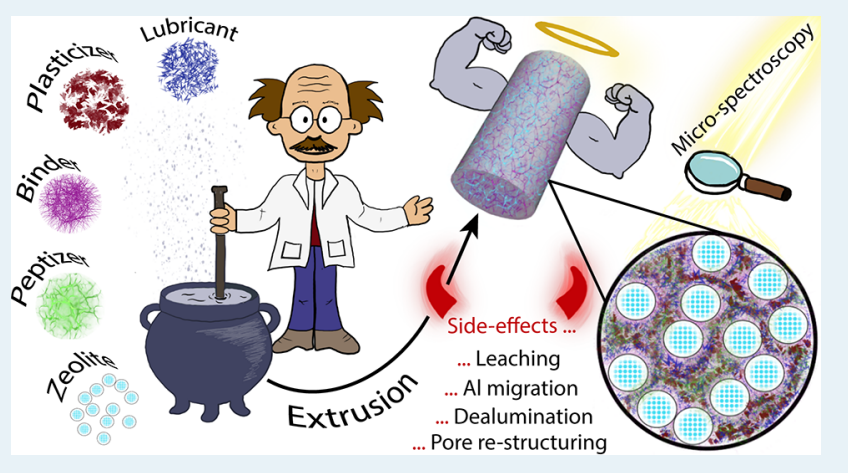
research into the unintentional impact organic additives can have on the properties of the zeolite and the catalyst bodies in general. Here, we systematically prepared a series of aluminabound zeolite ZSM-5-based catalyst bodies, with organic additives such as peptizing, plasticizing, and lubricating agents, to rationalize their impacts on the physicochemical properties of the shaped catalyst bodies. By utilizing a carefully selected arsenal of bulk and high-spatial resolution multiscale characterization techniques, as well as specifically sized bioinspired fluorescent nanoprobes to study pore accessibility, we clearly show that, although the organic additives achieve their primary function of a mechanically robust material, uncontrolled processes are taking place in parallel. We reveal that the extrusion process can lead to zeolite dealumination (from acid peptizing treatment, and localized steaming upon calcination); meso- and macropore structural rearrangement (via burning-out of organic plasticizing and lubricating agents upon calcination); and abating of known alumina binder effects (via scavenging of $\mathrm{Al}$ species via chelating lubricating agents), which significantly impact catalytic performance. Understanding the mechanisms behind such effects in industrial-grade catalyst formulations can lead to enhanced design of these important materials, which can improve process efficiency in a vast range of industrial catalytic reactions.

KEYWORDS: zeolites, extrudates, additives, binder, catalysis, catalyst body

\section{INTRODUCTION}

The role zeolite-based catalysts play in producing many of our everyday needs, such as fuels, chemicals, and materials, cannot be stressed enough. ${ }^{1-4}$ Their excellent physicochemical properties, such as well-defined pores/channels and tailored acidity, allow them to function efficiently in a variety of essential catalytic processes, such as alkylation, isomerization, and cracking. ${ }^{5-10}$ Normally, in an academic setting, the focus is heavily on "research" solid catalysts. Examples include zeolite single crystals and/or powders, which provide necessary fundamental insights into their catalytic properties. ${ }^{1-14}$ However, if they are to be used in industrial reactors, then more often than not, they are required to be scaled-up into shaped catalyst bodies. Here, the zeolite is dispersed in a binder/matrix/filler in a multiscale, multicomponent body, which, as compared to a powder, primarily limits pressure drop, enhances mechanical stability, and improves heat-mass transfer (among others). ${ }^{15,16}$ The process of forming shaped catalyst bodies, for example, catalyst extrudates, requires homogenization and densification of a proprietary formulation, to form a paste with an optimum solid-to-liquid ratio, prior to extrusion of green bodies and drying. Although experimental

Received: January 12, 2019

Revised: $\quad$ March 23, 2019

Published: April 26, 2019 
Scheme 1. (a) Illustration of a Freshly Extruded Zeolite-Catalyst Body, and the Distribution of Components Therein; ${ }^{a}$ and (b) (Non)primary Processes That Have Been Found To Occur in This Work, upon the Use of Additives in Zeolite-Based AluminaBound Catalyst Body Formulations
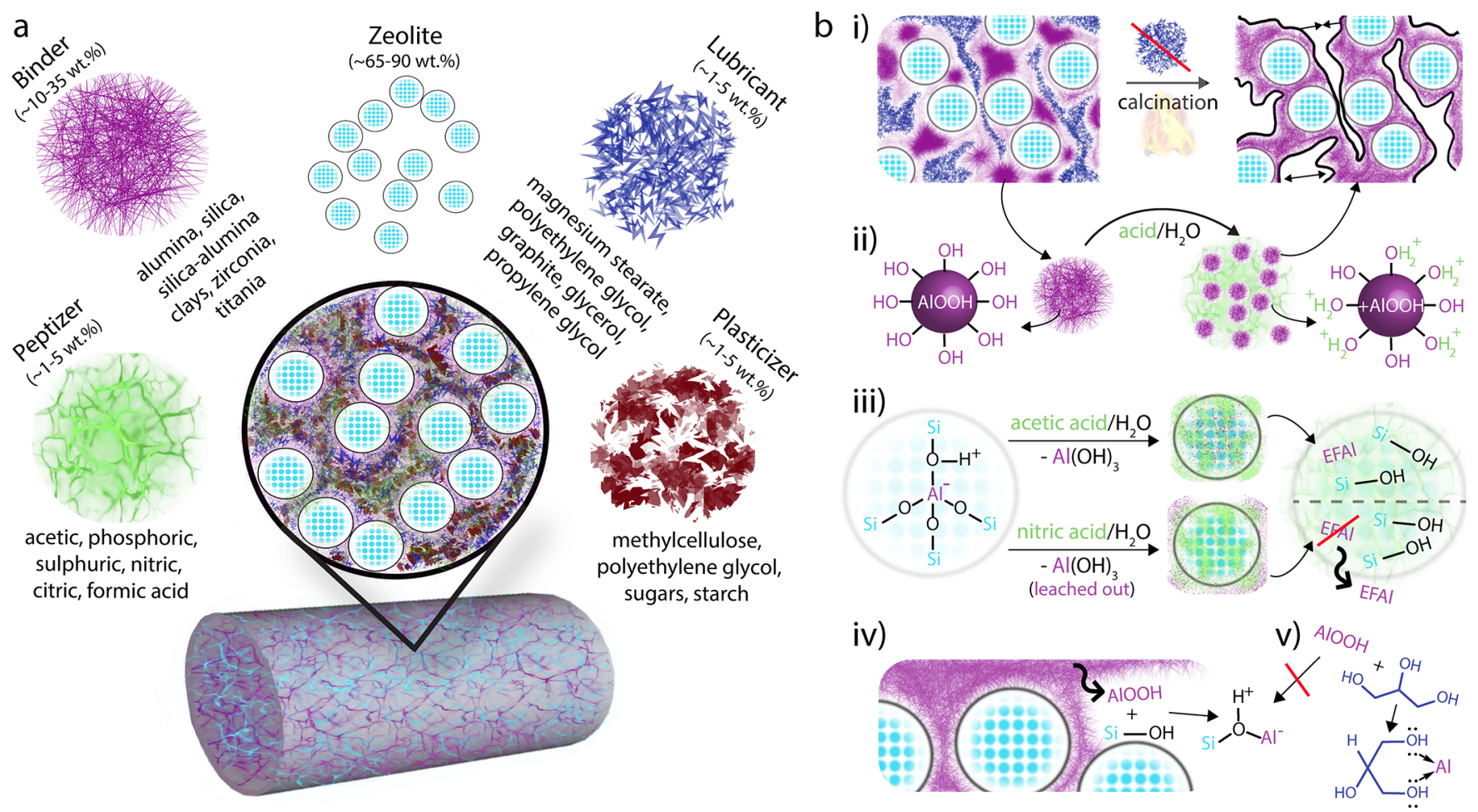

a (a) Examples are depicted of commonly employed inorganic components and organic additives burnt-off upon calcination. The primary role of each component/additive is as follows: zeolite is the active phase; binder provides mechanical strength to the technical body; peptizer disperses particles to achieve homogeneity; plasticizer enhances rheological behavior of the paste to be extruded; and lubricant aids the passage of the paste during extrusion into technical bodies. Typical amounts of each catalyst body are given on the basis of patent literature. ${ }^{19,20,42-46}(\mathrm{~b})(\mathrm{i})$ Lubricating and plasticizing agents effectively act as pore forming agents after their removal upon calcination, leading to variations in mesopore and macropore diameters/volume; (ii) peptizing agents lower the $\mathrm{pH}$ of the paste below the point zero charge (PZC) of the boehmite binder ( $\sim 9$ ), causing hydrolysis of the oxobridges between particles and protonation of the surface of the alumina binder, creating repulsion between particles; (iii) depending on the peptizing agent selected (i.e., acids with different $\mathrm{p} K_{\mathrm{a}}$ values), varying degrees of zeolite dealumination take place (with lower $\mathrm{pK}_{\mathrm{a}}$ values $(<1)$ leading to extra framework $\mathrm{Al}$ (EFAl) dissolution); (iv) $\mathrm{Al}$ migration taking place via mobile species from the $\gamma$ - $\mathrm{Al}_{2} \mathrm{O}_{3}$ binder to the zeolite, reacting with silanol groups (terminal framework and/or silanol nests (via dealumination)) to create additional acid sites; and (v) the use of lubricating agents such as glycerol can disrupt the prior-mentioned $\mathrm{Al}$ migration process, given the chelating nature of glycerol, depleting mobile $\mathrm{Al}$ species from the binder that could potentially form new acid sites.

details on the scale-up process are particularly vague, it is known that a large number of components are added to the formulation, that is, active phase, binder, filler, lubricant, plasticizer, porogen, and peptizing agents. ${ }^{16-21}$ Each of these components is added with a specific role(s) in mind, with the overall goal to achieve an extrudate with high mechanical strength, so as to withstand harsh reactor conditions. The primary function(s) of the organic additives used in the formulation design stems from a great deal of knowledge in the ceramics industry $^{22}$ and supported transition metal catalyst bodies. $^{23,24}$ For instance, peptizing agents such as acetic acid and citric acid are present to homogenize and disperse particles, and can be added in the form of acid or base. ${ }^{25}$ Lubricating and plasticizing agents like polyethylene glycol and cellulose are somewhat harder to distinguish from each other, as one compound can play both roles, but primarily their role is to reduce friction and decrease viscosity of the paste upon extrusion, with viscous oils and polar/nonpolar materials commonly employed. ${ }^{17}$ Unlike in ceramic extrudates/monoliths, components such as zeolites in catalyst bodies can potentially interact with organic additives prior to and during their decomposition upon drying. It has already been shown that side effects such as solid-state ion exchange between intimate binder and zeolite interactions can occur when shaping with a binder in zeolite-based catalyst bodies, being either beneficial or detrimental to their catalytic properties. ${ }^{26}$ Surprisingly, the binder component is often referred to as an inert material, mainly present to increase the mechanical properties of the catalyst body. However, past and more recent research has shed light on the significant impact the interaction of the binder can have on the zeolite active phase, such as entrapment of poisons, modification of deactivation characteristics, and neutralization of active sites, among others. ${ }^{27-36}$ Proximity of the binder and zeolite, together with the presence of water and heat treatment during shaping, ensure the transport of species from the binder to the zeolite (and vice versa), and solid-state ion exchange of the Brønsted acid sites takes place. The latter provides a definitive indication as to what consequences intimate contact between organic and inorganic components might have upon shaping.

It is therefore somewhat surprising to see that fundamental research into rationalizing the potential side effects of the 
organic additives in zeolite-based catalyst bodies is clearly lacking. Due to their individual physical and chemical characteristics, for example, structural dimensions and $\mathrm{pH}$, one can expect a large impact to the physicochemical properties of the zeolite and the catalyst body in general. For instance, the use of acidic solutions to dealuminate zeolites is well-known, ${ }^{37-39}$ so what happens to the zeolite acid sites in a shaped body when an acid peptizing agent is used in the formulation? Or indeed, what happens to the pore structure when lubricants of either short-chain polymers or long-chain polymers are burnt out upon drying? Each of these factors, among many possible others, has the potential to severely influence the catalytic properties of the final shaped catalyst bodies. Given the multidimensional nature of these important materials, together with the large number of components added, it is vital that a carefully chosen set of complementary, multiscale characterization techniques are used (e.g., electron microscopy, X-ray diffraction, solid-state nuclear magnetic resonance, etc.), ${ }^{40,41}$ as well as employing a rational approach to investigate the effect of formulations when preparing these catalyst bodies.

In this work, to elucidate the side effects organic additives can have on the catalytic properties of zeolite-based catalyst bodies, we have systematically prepared a series of aluminabound zeolite ZSM-5 catalyst bodies, adding commonly employed additives both separately and combined (Scheme 1), together with multiple state-of-the-art and novel multiscale characterization techniques. Such knowledge can lead to improved design of these important materials, to enhance process efficiency in a multitude of industrial catalytic processes.

\section{EXPERIMENTAL SECTION}

2.1. Shaped Catalyst Body Preparation. Zeolite HZSM-5 (ACS Materials, M38) was mixed as a dry powder with alumina (Sasol, Catapal D (Boehmite)) and the required amount of Milli-Q water to ensure an optimum solid-to-liquid ratio for extrusion (measured using a Mixer Torque Rheometer, Caleva). The paste, containing a ratio of 70:30 wt $\%$ zeolite:binder, was extruded using a Mini-Screw Extruder (Caleva), through a $2 \mathrm{~mm}(\varnothing)$ cylindrical die plate. To determine the effect of additives (e.g., peptizing agents, plasticizing agents, and/or lubricating agents), 2 wt \% acetic acid (Merck-Chemicals, glacial 100\%), nitric acid (Fluka, $>65 \%$ ), methylcellulose (Sigma-Aldrich, $4000 \mathrm{CP}$ ), polyethylene glycol (Sigma-Aldrich, $M_{n} 400$ ), and glycerol (Acros Organics, 83.5-88.5 wt \%) were either combined or added separately. After being dried overnight at room temperature, the extrudates were calcined in a tubular oven furnace at 600 ${ }^{\circ} \mathrm{C}$ for $6 \mathrm{~h}\left(5^{\circ} \mathrm{C} \mathrm{min}^{-1}\right)$ in flowing air. As a reference, a zeolite ZSM-5 extrudate was also prepared using the same method as above, but without the use of additives (i.e., only Milli-Q water). Sample names were labeled according to those in Chart 1.

2.2. Physicochemical Characterization. Ar physisorption of the catalyst bodies was performed using a Micromeritics TriStar 3000 instrument. Before the measurements, the samples were outgassed for $16 \mathrm{~h}$ at $300{ }^{\circ} \mathrm{C}$ under dry $\mathrm{N}_{2}$ flow, with measurements performed using $\mathrm{Ar}$ at $-196^{\circ} \mathrm{C}$. $\mathrm{Hg}$ porosimetry was measured in a Micromeritics Autopore IV 9500 instrument. A contact angle of $130^{\circ}$ for $\mathrm{Hg}$ intrusion and a pressure equilibration of $10 \mathrm{~s}$ were applied. Scanning electron microscopy (SEM) was performed using a FEI Helios Nanolab
Chart 1. Shaped Catalyst Body Formulations As Prepared in This Work ${ }^{a}$

\begin{tabular}{|c|c|c|c|}
\hline Sample & $\begin{array}{c}\text { Peptizers } \\
{ }_{\mathrm{H}_{3} \mathrm{C}} \stackrel{\Lambda}{O H}_{\mathrm{O}} \\
\text { (AA) } \\
\vdots^{\circ} \\
\text { (NA) }\end{array}$ & $\begin{array}{l}\text { Plasticizer } \\
\text { (MC) }\end{array}$ & $\begin{array}{l}\text { Lubricants } \\
\text { (PEG) } \\
\text { (GLY) }\end{array}$ \\
\hline ZSM-5 & $x$ & $x$ & $x$ \\
\hline$\gamma-\mathbf{A l}_{2} \mathbf{O}_{3}$ & $\checkmark(\mathrm{AA})$ & $\checkmark$ & $x$ \\
\hline EXT-1 & $x$ & $x$ & $x$ \\
\hline EXT-2 & $\checkmark(\mathrm{AA})$ & $x$ & $x$ \\
\hline EXT-3 & $x$ & $\checkmark$ & $x$ \\
\hline EXT-4 & $\checkmark(\mathrm{AA})$ & $\checkmark$ & $x$ \\
\hline EXT-5 & $\checkmark(\mathrm{NA})$ & $\checkmark$ & $x$ \\
\hline EXT-6 & $\checkmark(\mathrm{AA})$ & $\checkmark$ & $\checkmark(\mathrm{PEG})$ \\
\hline EXT-7 & $\checkmark(\mathrm{AA})$ & $\checkmark$ & $\checkmark(\mathrm{GLY})$ \\
\hline
\end{tabular}

${ }^{a}$ AA (acetic acid); NA (nitric acid); MC (methylcellulose); PEG (polyethylene glycol); GLY (glycerol).

G3 instrument, and, prior to analysis, the extrudate cross sections were coated with a layer of $\mathrm{Pt}$ to increase the conductivity of the samples. X-ray diffraction (XRD) patterns of the catalyst bodies (crushed and flattened) were recorded on a Bruker D8 X-ray powder diffractometer equipped with a Co $\mathrm{K} \alpha \mathrm{X}$-ray tube $(\lambda=1.7902 \AA)$. Prior to scanning transmission electron microscopy (STEM) analysis, samples were embedded in Epofix resin and dried in air at $60{ }^{\circ} \mathrm{C}$ overnight. The cured resin was then sliced into $70 \mathrm{~nm}$ thick sections with a Diatome Ultra $35^{\circ}$ diamond knife using a Reichert-Jung Ultracut E ultramicrotome. The obtained sections were deposited on Formvar carbon TEM grids. High-angle annular dark-field (HAADF)-STEM imaging and EDX mapping were performed on a Talos F200X (FEI) microscope, operated at $200 \mathrm{kV}$, which is equipped with an XFEG electron source and a Super-X detector. HAADF-STEM images were acquired with a frame time of $20 \mathrm{~s}$ using TIA software. STEM-EDX elemental maps of $512 \times 512$ pixels were acquired with $10 \mathrm{~min}$ acquisition time using Velox software. Crush strength measurements were performed on similarly sized single horizontal extrudates using a homemade load cell. To ensure reproducibility, extrudates were tested three times per sample, and the average crush strength was taken. Acidity measurements were recorded with a Nicolet iZ10-IR spectrometer at $2 \mathrm{~cm}^{-1}$ optical resolution using pyridine and collidine as probe molecules. Prior to the measurements, $20 \mathrm{mg}$ of the catalysts was pressed in selfsupporting discs (diameter: $1.6 \mathrm{~cm}$ ) and pretreated in the IR cell attached to a vacuum line at $450{ }^{\circ} \mathrm{C}$ for $4 \mathrm{~h}$ up to $10^{-6}$ Torr. Adsorption of pyridine and collidine (2,4,6-trimethylpyridine) was performed at $100{ }^{\circ} \mathrm{C}$ at the pressure of 1 Torr for $30 \mathrm{~min}$ to reach saturation, followed by evacuation at the same temperature for $30 \mathrm{~min}$. The desorption of the probe molecules was further monitored in the $100-450{ }^{\circ} \mathrm{C}$ temperature range with a $1{ }^{\circ} \mathrm{C} \mathrm{min}^{-1}$ heating rate. All spectra were normalized to $20 \mathrm{mg}$ wafers. Difference spectra were obtained by subtracting the spectrum of the zeolite before probe adsorption. The amount of adsorbed probe molecules was determined by using the integrated area of a given band with the molar extinction coefficients (Brønsted, $1.36 \mathrm{~cm}$ 


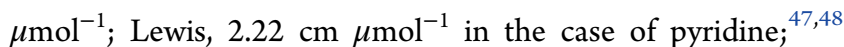
and Brønsted, $8.1 \mathrm{~cm} \mu \mathrm{mol}^{-1}$ when collidine was used as a probe $\left.{ }^{49}\right)$. More information on the calculation method can be found in Figures S4 and S5. Direct excitation ${ }^{29} \mathrm{Si} \mathrm{NMR} \mathrm{spectra}$ of catalyst extrudates were recorded on a Bruker $500 \mathrm{MHz}$ wide-bore magnet with an AVANCE-III console and equipped with a $3.2 \mathrm{~mm}$ magic angle spinning (MAS) probe, using direct excitation with a $90^{\circ}$ pulse (10 s recycle delay and $15 \mathrm{kHz}$ MAS frequency). For all experiments, ${ }^{29} \mathrm{Si}$ spectra were averaged over 3200 scans. The silicon to aluminum (FAl) ratio was estimated using Lowenstein's Rule and using eq $1,{ }^{50}$ where $I$ denotes the intensity of the ${ }^{29} \mathrm{Si} \mathrm{NMR}$ signal and $n_{\max }$ $=1$ in the present case.

$$
\left(\frac{\mathrm{Si}}{\mathrm{Al}_{\mathrm{F}}}\right)_{\mathrm{NMR}}=\sum_{n=0}^{4} \frac{I_{\mathrm{Si}(n \mathrm{Al})}}{\sum_{n=0}^{4} 0.25 n I_{\mathrm{Si}(n \mathrm{Al})}}
$$

2.3. Staining and Visualization. The $\sim 20$ and $\sim 45 \mathrm{~nm}$ fluorescent nanospheres (FluoSpheres, carboxylate-modified microspheres in Milli-Q water, ThermoFisher Scientific) were impregnated into each of the extrudates until saturation and equilibration $(24 \mathrm{~h})$, before drying under atmospheric conditions, bisectioning, and imaging with a 488 and 642 $\mathrm{nm}$ laser, respectively. Imaging was performed using a confocal fluorescence Nikon Eclipse 90i microscope equipped with a pinhole to filter out-of-focus light, and dichroic mirrors corresponding with the relevant laser line wavelength were chosen. The microscope was equipped with a Nikon Al scan head, accommodating the optics, which couple fiber optics for excitation and emission light with the microscope. A Nikon $10 \times / 0.30$ objective was used along with a spectral analyzer in the Nikon A1 system, equipped with 32 photomultiplier tubes (PMTs), set to collect emission light in the 487-720 nm region (resolution of $10 \mathrm{~nm}$ ). 3-D reconstruction of the individual imaged slices produced volumes of $1.29 \times 1.29 \times$ $\sim 0.5 \mathrm{~mm}$ ( $x, y, z$ (depth), respectively), visualized as "topview" images.

2.4. Thiophene Oligomerization Reaction. Timeresolved UV-vis diffuse-reflectance spectra were recorded using a high-temperature UV-vis fiber optics probe, connected to an AvaSpec 2048L spectrometer and an AvaLight-DH-SBAL light source. The measurements were performed using an in situ cell (Linkam Scientific Instruments, FTIR 600) equipped with a temperature controller (Linkam Scientific Instruments TMS 94). $\sim 10 \mu \mathrm{L}$ of thiophene was dropped on the extrudates at room temperature and immediately heated to $120{ }^{\circ} \mathrm{C}$ with a ramping rate of $30{ }^{\circ} \mathrm{C} \mathrm{min}^{-1}$. The absorption spectra were simultaneously recorded every $10 \mathrm{~s}$ for a total of $1000 \mathrm{~s}$ in reflectance mode.

\section{RESULTS AND DISCUSSION}

To systematically determine the potential side effects produced by organic additives included in zeolite-based alumina-bound catalyst bodies formulations, a selection of peptizing, plasticizing, and lubricating agents were added both individually and combined, prior to full characterization of their physicochemical properties, and finally evaluation of their effect on catalytic properties and performance.

3.1. Peptizing Agents. The main role of the peptizing agent (Figure 1) when preparing catalyst extrudates is to lower the $\mathrm{pH}$ of the paste (in relation to its point zero charge). This is done to break up agglomerates by creating positively charged particles (repulsion) that lead to lower viscosity, and favorable
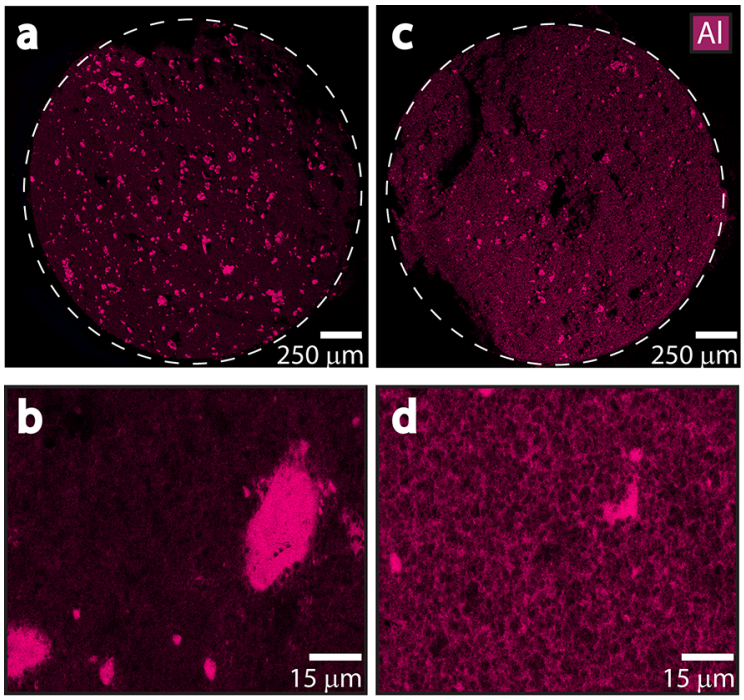

Figure 1. The Al-energy dispersive X-ray (EDX) mapping of (a) full cross-section of EXT-1, with large clusters of $\mathrm{Al}$ heterogeneously distributed, representative of the $\gamma-\mathrm{Al}_{2} \mathrm{O}_{3}$ binder (dotted white circle indicates the outer surface of the extrudate cross-section); (b) representative magnification of (a), with clusters of $\mathrm{Al}_{2} \mathrm{O}_{3}$ clearly visible with sparse $\mathrm{Al}$ distribution; (c) full cross-section of EXT-2, with $\mathrm{Al}$ more homogeneously distributed upon peptization; and (d) representative magnification of $(\mathrm{c})$, clearly displaying the homogeneous "honeycomb" network of the $\mathrm{Al}_{2} \mathrm{O}_{3}$ binder.

extrusion. ${ }^{16}$ An important factor to take into account is the need to homogeneously disperse the zeolite and binder throughout the resulting catalyst extrudate. When $\mathrm{Al}_{2} \mathrm{O}_{3}$ is selected as a binder, peptizing agents are considered necessary, so as to achieve a high zeolite dispersion. To determine the effect of peptizing agents on the physicochemical properties of alumina-bound zeolite ZSM-5-based extrudates, such catalyst bodies were prepared without and with acetic acid $\left(\mathrm{p} K_{\mathrm{a}} 4.75\right)$ (EXT-1 and EXT-2, respectively), a commonly used peptizing agent. $^{23,24,51}$

Although X-ray diffraction (XRD) patterns showed no change in phase and/or crystallinity of the zeolite ZSM-5 and $\gamma-\mathrm{Al}_{2} \mathrm{O}_{3}$ (Figure $\mathrm{S} 1$ ), scanning electron microscopy (SEM)EDX mapping revealed the difference in the distribution of $\mathrm{Al}$ and $\mathrm{Si}$ before (EXT-1) and after (EXT-2) the peptization process vividly, as shown in Figures 1 and S2. In EXT-1 (Figure 1a), Al clearly visible in the SEM image as clusters is predominantly present as large particles of $\gamma-\mathrm{Al}_{2} \mathrm{O}_{3}$ in the range of $5-40 \mu \mathrm{m}$ (Figure $1 \mathrm{~b}$ ) heterogeneously distributed throughout the entire cross-section. The Si distribution (Figure S2a) is attributed to the location of zeolite ZSM-5 domains that are homogeneously distributed. However, EXT-2 (Figures $1 \mathrm{c}$ and S2b) has a far more uniform distribution of $\mathrm{Al}$ throughout the cross-section, with significantly fewer large clusters of $\gamma-\mathrm{Al}_{2} \mathrm{O}_{3}$ present. Taking a closer look at the interaction of the $\gamma-\mathrm{Al}_{2} \mathrm{O}_{3}$ with the ZSM-5 crystals/aggregates (Figure S2c and d), the binding role of the $\gamma-\mathrm{Al}_{2} \mathrm{O}_{3}$ is vividly clear in the peptized sample (EXT-2) as compared to the nonpeptized sample (EXT-1), with a "honeycomb" of $\gamma-\mathrm{Al}_{2} \mathrm{O}_{3}$ surrounding zeolite domains in the former (Figure 1d). This is also evidenced by the crush-strength testing of both extrudates (Table 1 and Figure S3), with the peptized sample displaying a far superior strength (13 Newton (force required to crush/ break the catalyst bodies)) as compared to the nonpeptized $(3.5 \mathrm{~N})$ and the pure zeolite ZSM-5 extrudate $(2.5 \mathrm{~N})$. 
Table 1. Physicochemical Properties of ZSM-5-Based Extrudates

\begin{tabular}{|c|c|c|c|c|c|c|c|}
\hline Sample & $\begin{array}{c}\text { BET S.A. } \\
\left(\mathrm{m}^{2} \mathrm{~g}^{-1}\right)\end{array}$ & $\begin{array}{c}V_{\text {meso }^{b}} \\
\left(\mathrm{~cm}^{3} \mathrm{~g}^{-1}\right)\end{array}$ & $\begin{array}{c}V_{\text {macro }}^{b} \\
\left(\mathrm{~cm}^{3} \mathrm{~g}^{-1}\right)\end{array}$ & $\begin{array}{c}\mathbf{B A S}^{c} \\
\left(\mu \mathrm{mol} \mathrm{g^{-1 }}\right)\end{array}$ & $\begin{array}{c}\mathbf{B A S}^{d} \\
\left(\mu \mathbf{m o l} \mathbf{g}^{-1}\right)\end{array}$ & 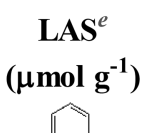 & $\begin{array}{c}\text { Crush } \\
\text { strength }^{g} \\
\text { (N) }\end{array}$ \\
\hline ZSM-5 & 556 & 0.18 & - & 342 & 5 & 41 & $2.5 \pm 0.2$ \\
\hline$\gamma-\mathbf{A l}_{2} \mathbf{O}_{3}$ & 285 & 0.02 & 0.50 & 0 & 0 & 293 & $20 \pm 10.2$ \\
\hline EXT-1 & 345 & 0.02 & 0.60 & 314 & 2 & 141 & $3.5 \pm 0.8$ \\
\hline EXT-2 & 347 & 0.04 & 0.36 & 345 & 11 & $176(129)^{f}$ & $13 \pm 0.4$ \\
\hline EXT-3 & 336 & 0.01 & 0.43 & 321 & 3 & 151 & $17 \pm 6.0$ \\
\hline EXT-4 & 319 & 0.02 & 0.35 & 396 & 12 & 165 (129) & $25 \pm 2.8$ \\
\hline EXT-5 & 352 & 0.03 & 0.30 & 408 & 12 & 133 (129) & $23 \pm 2.4$ \\
\hline EXT-6 & 336 & 0.02 & 0.30 & 328 & 12 & $171(129)$ & $17 \pm 4.5$ \\
\hline EXT-7 & 214 & 0.01 & 0.33 & 340 & 9 & 147 (129) & $21 \pm 7.7$ \\
\hline
\end{tabular}

${ }^{a}$ Measured using Ar physisorption. ${ }^{b}$ Volume of meso- $(3-50 \mathrm{~nm}$ in diameter) and macropores ( $>50 \mathrm{~nm})$ measured using Hg intrusion. ${ }^{c}$ Concentration of Brønsted acid sites (BAS) per gram of zeolite in the sample, measured by pyridine adsorption IR (peak at $1545 \mathrm{~cm}^{-1}$ ). ${ }^{d}$ Concentration of Brønsted acid sites (BAS) per gram of zeolite in the sample, measured by collidine adsorption IR spectroscopy. ${ }^{e}$ Concentration of Lewis acid sites (LAS) per gram of extrudate material, measured by pyridine adsorption IR (peak at $1454 \mathrm{~cm}^{-1}$ ). ${ }^{f}$ Predicted value based on experimental values and wt $\%$ of the pure components (ZSM-5 and peptized $\gamma-\mathrm{Al}_{2} \mathrm{O}_{3}$ ) present in the catalyst extrudate material. ${ }^{g}$ Average crushstrength measurements on similarly sized single catalyst extrudates, with the standard deviation also shown (Figure S3).

To reveal a higher degree of detail about the location and interaction of zeolite ZSM-5 and $\gamma-\mathrm{Al}_{2} \mathrm{O}_{3}$ in both EXT-1 and EXT-2, transmission electron microscopy (TEM)-EDX studies were performed on $70 \mathrm{~nm}$ thin sections of extrudates prepared by ultramicrotomy, and are presented in Figures 2 and S4.
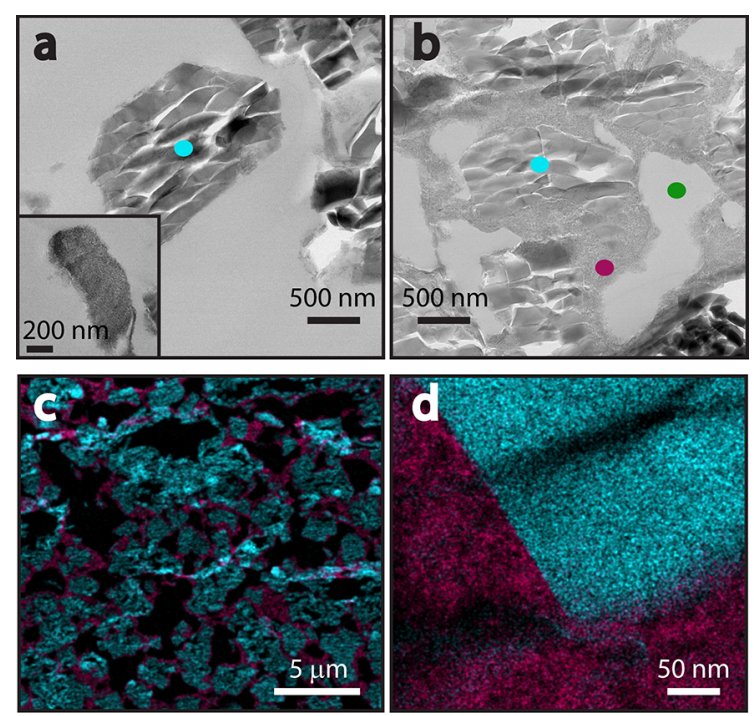

Figure 2. TEM images of (a) EXT-1 and (b) EXT-2. The ZSM-5 crystal (highlighted by blue dot centered in the crystal) in EXT-1 is coated with a thin layer of $\gamma-\mathrm{Al}_{2} \mathrm{O}_{3}$, while the remaining $\gamma-\mathrm{Al}_{2} \mathrm{O}_{3}$ appears to be isolated in large aggregates (inlay). In EXT-2, a significantly higher quantity of $\gamma-\mathrm{Al}_{2} \mathrm{O}_{3}$ is visible as smaller aggregates (magenta dot) binding ZSM-5 crystals. Pore space is indicated via a green dot. (c) EDX map ( $\mathrm{Al}$ in magenta, $\mathrm{Si}$ in blue) of EXT-2, showing the homogeneous binding of the zeolites by $\gamma-\mathrm{Al}_{2} \mathrm{O}_{3}$. Pore space is displayed in black regions (note, small black "cracks" within the blue $\mathrm{Si}$ (zeolite) domains are an artifact of the TEM preparation procedure, not intrinsic zeolite porosity). (d) Magnified EDX map of a single ZSM-5 crystal very tightly bound with $\gamma-\mathrm{Al}_{2} \mathrm{O}_{3}$ along the very well-defined zeolite edge (corresponding TEM image displayed in Figure S4d).
Looking first at EXT-1, single zeolite ZSM-5 crystals are visible in Figure 2a, with no clear indication that $\gamma-\mathrm{Al}_{2} \mathrm{O}_{3}$ is present around the zeolite crystals. However, a more detailed analysis (Figure S4a) reveals a thin layer (20-40 nm in thickness) of $\gamma$ $\mathrm{Al}_{2} \mathrm{O}_{3}$ on the ZSM-5 crystal surface, and appears to be the case on a larger scale as well (Figure $\mathrm{S} 4 \mathrm{~b}$ ). Therefore, it seems that smaller particles of $\gamma-\mathrm{Al}_{2} \mathrm{O}_{3}$ powder are gathered onto the external surface of ZSM-5 crystals/aggregates during the extrusion process and create a fixed zeolite-boehmite interaction upon subsequent calcination, while the larger $\gamma$ $\mathrm{Al}_{2} \mathrm{O}_{3}$ clusters remain unbroken, giving rise to limited binding properties in EXT-1. On the contrary, $\gamma-\mathrm{Al}_{2} \mathrm{O}_{3}$ is distinctly more dispersed in a similarly sized region within EXT-2 (Figures 2b,c and S4c). Single ZSM-5 crystals are fully enveloped by $\gamma-\mathrm{Al}_{2} \mathrm{O}_{3}$ (Figures $2 \mathrm{~d}$ and $\mathrm{S} 4 \mathrm{~d}$ ), due to a greater dispersion of $\gamma-\mathrm{Al}_{2} \mathrm{O}_{3}$ and thus smaller aggregates, which lead to higher zeolite-binder interconnectivity and hence stronger mechanical properties of EXT-2 (Table 1). Considering the higher crush strength attributes (Table 1 and Figure S3) of EXT-2, these extrudates are able to survive the dedicated TEM preparation procedure, and hence macro- and mesopore space is visible in EXT-2 (Figure 2b) as compared to that of the disintegrated region visible in EXT-1 (Figure S4b).

To probe bulk porosity characteristics, $\mathrm{Hg}$ intrusion analysis (Figure $3 \mathrm{a}$ and Table 1) was used to analyze both meso- and macroporosity in EXT-1 and EXT-2. Upon the use of acetic acid, there is a clear decrease in around one-half the macropore volume $\left(0.60 \mathrm{~cm}^{3} \mathrm{~g}^{-1}\right.$ EXT-1 and $0.36 \mathrm{~cm}^{3} \mathrm{~g}^{-1}$ EXT-2), accompanied by a doubling in mesopore volume $\left(0.02 \mathrm{~cm}^{3} \mathrm{~g}^{-1}\right.$ for EXT-1 and $0.04 \mathrm{~cm}^{3} \mathrm{~g}^{-1}$ EXT-2). This can be attributed to the hydrolysis of the oxobridges between alumina particles and protonation of the surface of the alumina binder, creating repulsion between particles (Figure 1$).^{16}$ It is also possible to vary the acid/alumina ratio, to tailor the particle size distribution, and hence the final pore architecture. ${ }^{52}$ Deagglomeration of the alumina effectively decreases its aggregate size, and leads to more interparticle interactions with other alumina particles, as well as zeolite ZSM-5 particles, coinciding with an increase in mesopore volume/diameter. 

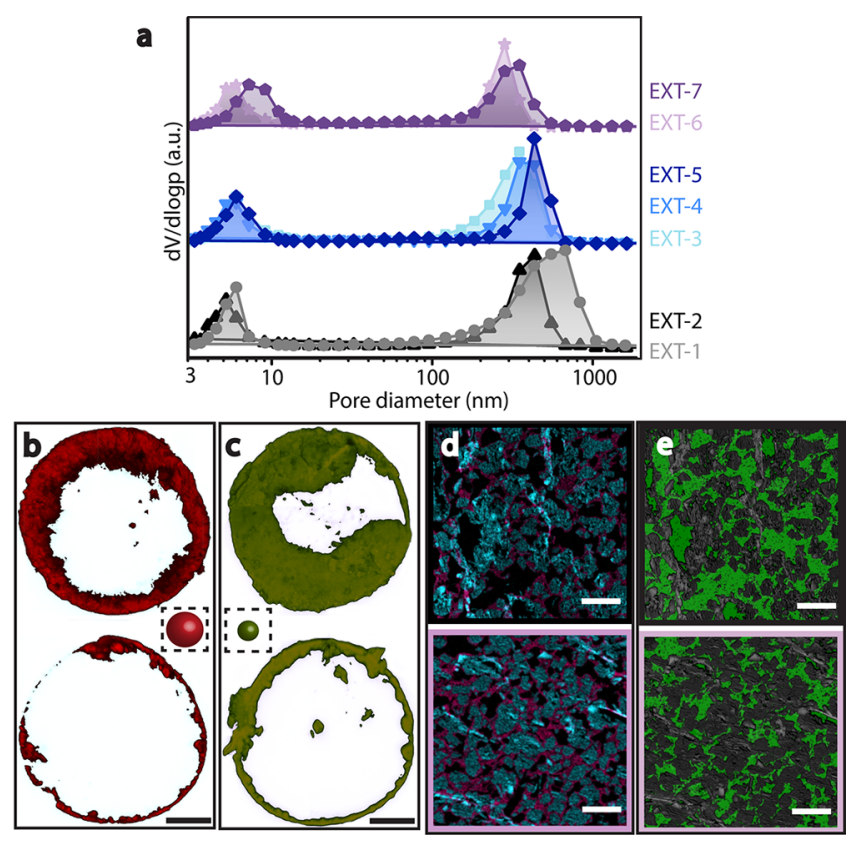

Figure 3. (a) $\mathrm{Hg}$ intrusion analysis displaying pore diameter variations between EXT-1 (gray, -) and EXT-2 (black, $\mathbf{\Delta}$ ). (b) Fluorescence top-view 3-D CFM images of cross sections of EXT-1 (top) and EXT-2 (bottom) impregnated with $45 \mathrm{~nm}$ fluorescent nanospheres (for $24 \mathrm{~h}$ ) and excited with a $642 \mathrm{~nm}$ laser. EXT-1 shows a far higher penetration depth into the center of the extrudate as compared to EXT-2. (c) True fluorescence top-view cross-sectional 3D CFM images of EXT-1 (top) and EXT-2 (bottom), impregnated with $20 \mathrm{~nm}$ fluorescence nanospheres (for $24 \mathrm{~h}$ ) and excited with a $488 \mathrm{~nm}$ laser. The smaller size of the probe allows further penetration into the center of both extrudates, with a greater effect seen for EXT-1 (scale bars represent $500 \mu \mathrm{m}$ ). (d) TEM-EDX maps of sections of EXT-2 (black) and EXT-6 (light purple), with Si (light blue) attributed to zeolite domains and $\mathrm{Al}$ (magenta) mainly attributed to alumina binder domains (scale bar represents $5 \mu \mathrm{m}$ ). (e) Corresponding dark pixel intensity threshold images of those displayed in (d), with marked green regions highlighting the pore space observed. In line with $\mathrm{Hg}$ porosimetry data, EXT-2 reveals larger pore space overall as compared to EXT-6.

Considering the porosity differences highlighted by $\mathrm{Hg}$ intrusion in EXT-1 and EXT-2, an attempt was made to visualize the accessibility of these pores using bioinspired fluorescent nanospheres of specific sizes, coupled with confocal fluorescence microspectroscopy (CFM) to visualize the nanosphere uptake/accessibility. ${ }^{53}$ By impregnating EXT-1 and EXT-2 with a solution containing either $\sim 45$ or $\sim 20 \mathrm{~nm}$ nanospheres, prior to excitation with a $642 \mathrm{~nm}$ laser or $488 \mathrm{~nm}$ laser, respectively, regions of accessibility can be visualized. Figure $3 \mathrm{~b}$ compares the top-view 3-D cross sections of EXT-1 and EXT-2 impregnated with $\sim 45 \mathrm{~nm}$ nanospheres, respectively. A more substantial penetration depth is observed for EXT-1, stopping at around $250-300 \mu \mathrm{m}$ in the $2 \mathrm{~mm}(\varnothing)$ extrudate. Considering the expected larger macropore volume due to the heterogeneous $\gamma-\mathrm{Al}_{2} \mathrm{O}_{3}$ aggregate size in EXT-1, it is possible that, upon drying/calcination, water is first removed efficiently and rapidly from the outer region of the cylindrical catalyst extrudate, leaving a region of larger and more accessible pores than in the core. There is only minimal penetration into EXT-2 $(\sim 50 \mu \mathrm{m})$, suggesting that the narrower pore network formed upon $\gamma-\mathrm{Al}_{2} \mathrm{O}_{3}$ particle peptization exists throughout the majority of the catalyst extrudate cross-section and is less accessible and/or less interconnected.

To probe accessibility into such smaller pore space in both extrudates, $20 \mathrm{~nm}$ fluorescent nanospheres were applied (Figure $3 c$ ), revealing an even deeper penetration into EXT$1(>500 \mu \mathrm{m})$ and to a far lower extent in EXT-2 $(<100 \mu \mathrm{m})$. It is clear, therefore, that a gradient of larger to smaller pores and/or a decrease in interconnected pores exists from outside to inside the extrudates, with the constituent particle sizes highly influential in determining the final pore architecture. Interestingly, the penetration of the nanospheres is not equal across all sides of EXT-1, which is most likely due to the heterogeneous drying nature of a tubular oven calcination setup (i.e., catalyst extrudates at the bottom of the calcination boat experience inconsistent heat/air flow).

It is clear that the use of a peptizing agent achieves its intended aim by producing a much stronger extrudate, with the active and binder components more homogeneously dispersed than when absent. However, as stated previously, the use of acid solutions and heat treatment is a well-known method of zeolite dealumination. ${ }^{37-39}$ Therefore, the use of an acid peptizing agent during the extrusion of alumina-bound zeolite ZSM-5 and its subsequent calcination should surely influence the final zeolite properties. Infrared (IR) spectroscopy of adsorbed probe molecules and solid-state ${ }^{29} \mathrm{Si}$ MAS NMR were employed to analyze the amount of both Brønsted (BAS) and Lewis (LAS) acid sites, as well as to determine if zeolite framework dealumination has taken place in the ZSM-5-based catalyst bodies. The amount of BAS present in the parent zeolite ZSM-5 extrudate and EXT-2 upon pyridine adsorption/ desorption appears to be unchanged (Table 1 and Figure S5); however, it is clear that there is a large increase in the amount of LAS present in EXT-2 $\left(176 \mu \mathrm{mol} \mathrm{g}^{-1}\right)$ as compared to the predicted value $\left(129 \mu \mathrm{mol} \mathrm{g}^{-1}\right.$, using experimentally measured values of the pure zeolite and binder components). An increase in LAS is expected upon zeolite framework (FAl) dealumination, creating extra-framework aluminum (EFAl), which can act as LAS (Scheme 1). ${ }^{54}$ Deconvolution of the ${ }^{29}$ Si MAS NMR spectra enables a quantitative analysis of the $\mathrm{Si}$ tetrahedral sites, which can confirm if desilication or dealumination has taken place within the zeolite framework. ${ }^{55,56}$ Four peaks arise from the spectra of ZSM-5 and EXT-2 (Figure 4), centered at $-100,-106$, and -112 and $-116 \mathrm{ppm}$, which are attributed to $\left(\mathrm{Q}^{2}\right) \mathrm{SiOH},\left(\mathrm{Q}^{3}\right) \mathrm{Si}(3 \mathrm{Si}$, $1 \mathrm{Al})$, and $\left(\mathrm{Q}^{4}\right) \mathrm{Si}(4 \mathrm{Si})$, respectively. A decrease in $\mathrm{Q}^{3}$ species, coupled with an increase in $\mathrm{Q}^{2}$ species, is related to dealumination in the zeolite framework, which gives rise to a change in the framework Si:Al ratio from 20.9 (ZSM-5) to 21.8 (EXT-2) (via eq 1).

Given that the number of Lewis acid sites (LAS) increases upon shaping of ZSM-5 and its framework undergoes dealumination, the unchanged number of the Brønsted acid sites (BAS) from the parent ZSM-5 suggests a parallel process is also taking place. Although a full understanding of the mechanism is lacking, $\mathrm{Si}$ and/or $\mathrm{Al}$ migration has been reported upon the shaping of zeolites with an alumina or silica binder. $^{29,30,57,58}$ In the case of an alumina binder, Al species have been proposed to migrate from the binder to the zeolite, $^{59}$ whereby upon the interaction with $\mathrm{Si}$ and $\mathrm{O}$, additional acid sites can then be created (Scheme 1). However, there is some discrepancy in the mechanism of how this may occur, and also if these acid sites are created within the zeolite framework, or at the zeolite-binder interface. To observe if $\mathrm{Al}$ 

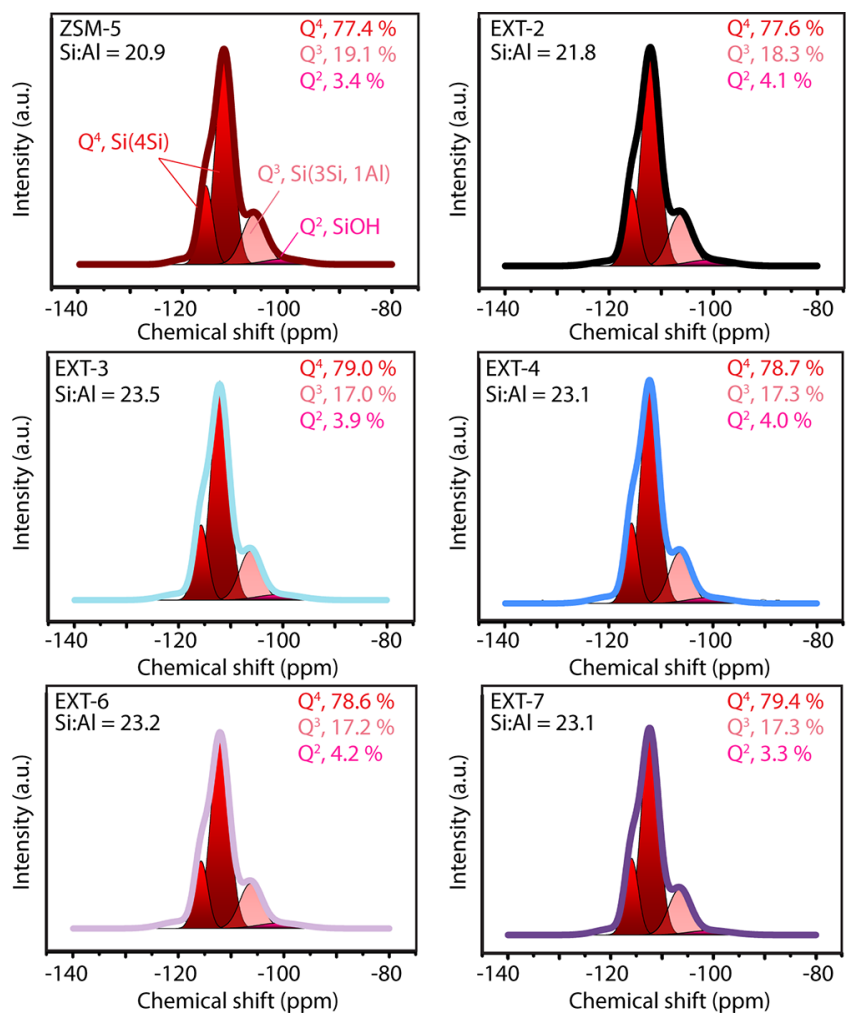

Figure 4. Direct-excitation ${ }^{29} \mathrm{Si}$ solid-state MAS NMR spectra of parent zeolite ZSM-5 and shaped zeolite ZSM-5 extrudates prepared with varying formulations. Si-species identified as $Q^{4}(-112$ and -116 $\mathrm{ppm}), \mathrm{Q}^{3}(-106 \mathrm{ppm})$, and $\mathrm{Q}^{2}(-100 \mathrm{ppm})$, with corresponding Si:Al calculated (cf., eq 1 ).

migration has indeed taken place during shaping (and peptization) and also to determine if acid site creation is indeed located at the zeolite-binder interface, collidine (Figure S6 and Table 1) was employed as a probe molecule instead of pyridine, to selectively probe the external BAS at the surface of the zeolites. A 2-fold increase in BAS located outside the zeolite pores was measured for EXT-2 as compared to the parent zeolite ZSM-5 extrudates, suggesting that Al migration has indeed taken place, creating new acid sites at the interface. The presence of an acid peptizing agent (EXT-2) appears to form $+\mathrm{AlOOH}$ species in the binder that are the species involved in Al migration (Scheme 1). Previously, it has been suggested that such species are capable of neutralizing BAS in the zeolite (via replacement of a $\mathrm{BAS} \mathrm{H}^{+}$with $\mathrm{AlO}^{+}$); ${ }^{60}$ however, this was not observed in our materials.

3.2. Plasticizing and Lubricating Agents. In most cases of zeolite shaping, particularly during extrusion, the use of additives such as plasticizing and lubricating agents is essential. Plasticizing agents (Scheme 1) offer a means to enhance the rheological behavior of the paste to be extruded, and are inorganic (e.g., clay) or organic (e.g., cellulose) in nature. The latter appears to be far more popular, given the range of possibilities, such as poly alcohols, alginates, celluloses, and sugars, among others. ${ }^{17}$ The choice is dependent on the material at hand, but it is not uncommon to include a vast number of these additives in a proprietary mixture. ${ }^{19}$ The same can be said for lubricating agents, which are used to aid the passage of the paste as it passes along the inner wall of the extrusion equipment, in effect lowering shear pressure. ${ }^{16}$ The role of the lubricating agent is sometimes not discernible from the plasticizing agent, and similar organic compounds are available, such as ethylene glycol and propylene glycol.

As with peptizing agents, these additives are used with a primary role in mind, and being organic in nature, are burnt out during drying/calcination of the shaped bodies, which can lead to unintentional physicochemical changes in the components of the extrudate. To discriminate the beneficial and detrimental roles of the plasticizing agent, methylcellulose was added to the formulation (without peptizing agent) prior to the extrusion of the paste (EXT-3). As compared to EXT-1 (no additives), a significant decrease in macropore volume from 0.60 to $0.43 \mathrm{~cm}^{3} \mathrm{~g}^{-1}$ (Table 1) and pore diameter within the macroporous region was observed (Figure 3a). The combustion of methylcellulose upon drying leads to it being driven out of the extrudate after initially lying between particles, which can cause interparticulate sintering, and hence macropore collapse. Measuring the crush strength of EXT-1 and EXT-3, it is clear that the primary role of the plasticizing agent has been achieved, with an increase from 3.5 to $17 \mathrm{~N}$, respectively. However, comparing the amount of BAS measured via pyridine adsorption of EXT-3 with that of the pure ZSM-5 extrudate, a slight decrease is observed, but is consistent with the decrease observed in EXT-1. For both EXT-1 and EXT-3, this decrease could be attributed to zeolite dealumination due to localized steaming of the zeolite from the water/methyl cellulose added during extrusion. This is observed by ${ }^{29} \mathrm{Si}$ MAS NMR in Figure 4 for EXT-3, with an even larger degree of zeolite FAl dealumination observed ( $\mathrm{Si}: \mathrm{Al}=23.5)$ as compared to those of EXT-2 (21.8) and the parent ZSM-5 (20.9). It is possible that the decomposition products of methylcellulose formed during calcination ${ }^{61}$ and their subsequent combination with water can locally dealuminate the zeolite crystals.

Although we have now investigated the effects of peptizing and plasticizing agents individually, these are commonly added jointly in a formulation. Interestingly, the combination of acetic acid and methylcellulose (EXT-4) leads to significant changes in physicochemical properties when compared to their separate use (EXT-2 and EXT-3, respectively). In terms of macropore properties, it appears that acetic acid has the bigger influence over methylcellulose, with $0.35 \mathrm{~cm}^{3} \mathrm{~g}^{-1}$ measured for EXT-4, consistent with $0.36 \mathrm{~cm}^{3} \mathrm{~g}^{-1}$ measured for EXT-2 (Table 1), and similar pore size distribution (Figure 3a). However, EXT-2 presents a mesopore volume of $0.04 \mathrm{~cm}^{3} \mathrm{~g}^{-1}$, which has now decreased to $0.02 \mathrm{~cm}^{3} \mathrm{~g}^{-1}$ upon incorporation of methylcellulose to the formulation (EXT-4), revealing the dominant role of the plasticizing agent on the mesopore properties (as observed in EXT-3). This suggests that acetic acid is still able to protonate the alumina binder particles, but as the methylcellulose is burnt out during calcination, the interparticle porosity, attributed to the mesopore volume, is decreased. The result of a decrease in both macropore and mesopore volume coincides with a further increase in extrudate strength, with a value of $25 \mathrm{~N}$ measured for EXT-4, as compared to that of $13 \mathrm{~N}$ (EXT-2) and $17 \mathrm{~N}$ (EXT-3), showing the beneficial combination of additives in this case.

Pyridine adsorption IR spectroscopy of EXT-4 revealed a remarkable increase in the amount of BAS $\left(396 \mu \mathrm{mol} \mathrm{g}^{-1}\right)$ when compared to those of parent ZSM-5 $\left(342 \mu \mathrm{mol} \mathrm{g}^{-1}\right)$, EXT-2 $\left(345 \mu \mathrm{mol} \mathrm{g}{ }^{-1}\right)$, and also EXT-3 $\left(321 \mu \mathrm{mol} \mathrm{g}^{-1}\right)$ (Table 1 and Figure S5). The large increase in BAS for EXT-4 as compared to that of EXT-2 indicates the combination of methylcellulose with the acetic acid further promotes $\mathrm{Al}$ 
a

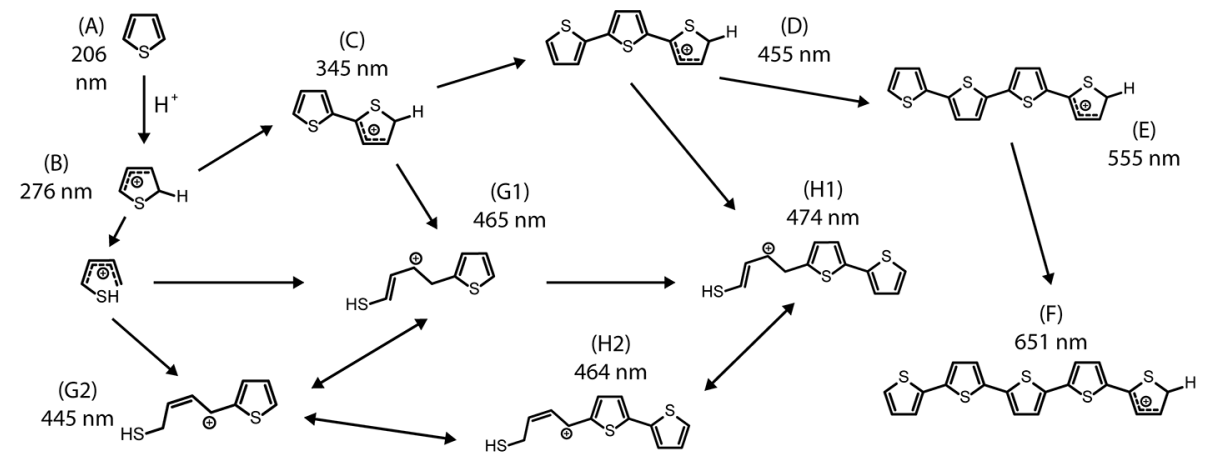

b

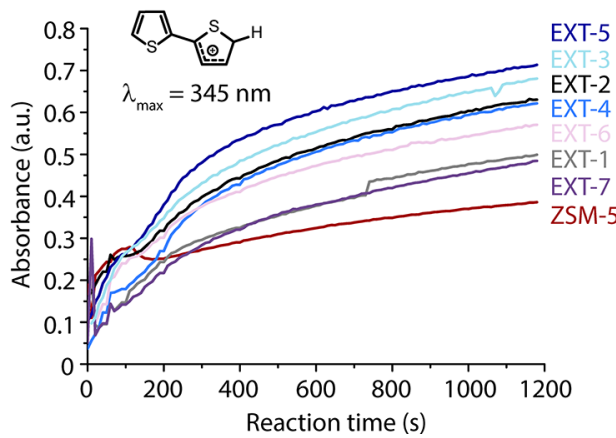

C

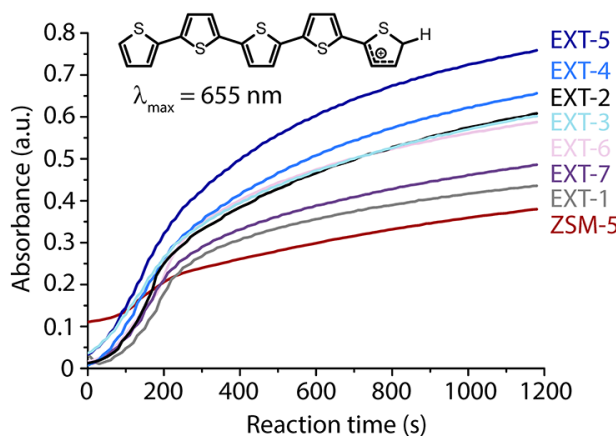

Figure 5. (a) Scheme displaying the oligomerization (top) and ring-opening (middle and lower) pathways taking place in zeolite Brønsted acid site-catalyzed thiophene oligomerization reaction. (b) Time-resolved $345 \mathrm{~nm}$ absorbance changes and (c) $655 \mathrm{~nm}$ absorbance changes, for each extrudate measured, showing that the trend in amount of total BAS (Table 1) is directly related to the absorbance intensity (normalized to ZSM-5 content) of the thiophene dimer, and that of the pentamer is directly related to the amount of external BAS (Table 1). (See Figure S8 for further details.)

migration from the binder to the zeolite, creating a greater amount of additional BAS. However, the comparable amount of external BAS measured using collidine of EXT-4 $(12 \mu \mathrm{mol}$ $\left.\mathrm{g}^{-1}\right)$ and EXT-2 $\left(11 \mu \mathrm{mol} \mathrm{g}^{-1}\right)$ suggests that not all newly created acid sites in EXT-4 are located at the zeolite-binder interface. This adds doubt to the theory that Al migration creates acid sites solely at the zeolite-binder interface, and realumination of the zeolite is now also a possibility. An increase in LAS was also observed $\left(165 \mu \mathrm{mol} \mathrm{g}^{-1}\right)$ for EXT-4 as compared to the predicted value calculated from the pure components $\left(129 \mu \mathrm{mol} \mathrm{g}^{-1}\right)$. This means that, although extra BAS are being created in EXT-4, dealumination of its zeolite $\mathrm{FAl}$ is still taking place, as expected and previously observed for EXT-2 and EXT-3, due to the presence and thermal treatment of acid, water, and methylcellulose upon calcination. This is again confirmed using the zeolite framework sensitive ${ }^{29} \mathrm{Si}$ MAS NMR (Figure 4), with an increase from Si:Al = 20.9 (ZSM-5) to 23.1 (EXT-4). Given the combination effect of the acetic acid and methylcellulose on the physicochemical properties of EXT-4, the effect of combining an alternative peptizing agent with methylcellulose was also investigated. Acetic acid was replaced by nitric acid (EXT-5), and a similar trend is observed, with some key differences. Not only is a larger decrease in macropore volume observed in EXT-5 as compared to EXT-4 ( 0.30 and $0.35 \mu \mathrm{mol} \mathrm{g}^{-1}$, respectively), but also a narrowing of the macropore diameter, as well as a slight increase in mesopore volume, and a decrease in the amount of LAS (Table 1). In each case, the higher acid strength of nitric acid $\left(\mathrm{pK}_{\mathrm{a}}<1\right)$ as compared to acetic acid $\left(\mathrm{p} K_{\mathrm{a}} 4.75\right)$ is the cause of these differences, as it creates a greater degree of particle deagglomeration and also leads to the dissolution of EFAl species upon dealumination, ${ }^{62}$ which will have drastic implications for its performance in BAS/LAScatalyzed reactions.

To determine the effects of lubricating agents, two commonly used organic compounds were added separately to the formulation of EXT-4, polyethylene glycol (EXT-6) and glycerol (EXT-7). Although both compounds achieved their primary goal by easing the extrusion process considerably, their overall physicochemical properties were markedly (and unintentionally) impacted. Pore volume analysis via $\mathrm{Hg}$ porosimetry (Table 1 and Figure $3 a$ ) shows a decrease in macropore volume in both EXT-6 $\left(0.30 \mathrm{~cm}^{3} \mathrm{~g}^{-1}\right)$ and EXT-7 $\left(0.33 \mathrm{~cm}^{3} \mathrm{~g}^{-1}\right)$ as compared to EXT-4 $\left(0.35 \mathrm{~cm}^{3} \mathrm{~g}^{-1}\right)$, with only a minor change in mesopore volume. However, their pore diameters differ significantly, with the macropore size distribution EXT-6 being substantially narrower (peak maxima centered at $282 \mathrm{~nm}$, as compared to $323 \mathrm{~nm}$ in EXT-7 and 390 $\mathrm{nm}$ in EXT-4). Furthermore, the mesopore diameter range in EXT-7 shifts to much larger diameters than all other extrudates (peak maxima at $7.7 \mathrm{~nm}$ ), specifically as compared to that of EXT-6 (peak maxima at $5.6 \mathrm{~nm}$ ). Such changes might not be expected from the primary role of these lubricating agents; however, these compounds are well-known pore forming agents (Scheme 1) in porous membrane synthesis, and pore sizes can even be tailored in the case of PEG, by altering its molecular weight. ${ }^{63}$

Although TEM cannot be solely relied upon for visualizing/ determining pore structure (due to sample preparation and region of interest (ROI) dimensions, representation, etc.), there is a clear indication that the macropore structure in EXT6 is much more compact than that in EXT-2 (Figure 3d and e), 
which could also explain the large decrease in BET surface area for EXT-6 (Table 1). This is further strengthened by pore accessibility measurements using fluorescent nanospheres in each of the above samples (Figures 3c and S7). Evidently, 20 $\mathrm{nm}$ nanospheres have difficulty in penetrating into EXT-6, which, due to the macropore diameters present in the region of 150-400 nm, suggests that these pores are not well interconnected or accessible from the outside of the extrudate, as compared to that of EXT-2, where an increasing amount of penetration of the nanospheres is observed (complementing $\mathrm{Hg}$ porosimetry and TEM results).

Probing of LAS in EXT-6 and EXT-7 using pyridine IR spectroscopy (Table 1) (171 and $147 \mu \mathrm{mol} \mathrm{g}^{-1}$, respectively) and ${ }^{29} \mathrm{Si}$ MAS NMR (Figure 4) ( $\mathrm{Si}: \mathrm{Al}=23.2$ and 23.1, respectively, as compared to $\mathrm{Si}: \mathrm{Al}=20.9$ for the pure $\mathrm{ZSM}-5$ ) again reveals a large degree of zeolite dealumination, similar to that of EXT-4 (LAS $=165 \mu \mathrm{mol} \mathrm{g}{ }^{-1}$ and $\mathrm{Si}: \mathrm{Al}=23.1$ ). However, a substantially lower amount of BAS is observed for EXT-6 $\left(328 \mu \mathrm{mol} \mathrm{g}{ }^{-1}\right)$ and EXT-7 $\left(340 \mu \mathrm{mol} \mathrm{g} \mathrm{g}^{-1}\right)$ as compared to EXT-4 $\left(396 \mu \mathrm{mol} \mathrm{\textrm {g } ^ { - 1 }}\right)$. Given the similar amounts of BAS of EXT-6 and EXT-7 to that of the parent ZSM-5 (345 $\left.\mu \mathrm{mol} \mathrm{g}^{-1}\right)$, it suggests that $\mathrm{Al}$ migration upon peptization and hydrothermal treatment is hindered in the presence of these lubricating agents (as compared to EXT-4). Considering that both PEG and glycerol are chelating agents, it is possible that their interaction with $\mathrm{Al}$ species inhibits their migration to the zeolite, effectively scavenging excess $\mathrm{Al}$ that would, in the case of EXT-4, create additional acid sites.

Given these dramatic physicochemical changes witnessed for EXT-4, EXT-6, and EXT-7, it is crucial to carefully investigate the choice of plasticizing/lubricating agents not only for their primary role, but also for their unintentional side effects in combination with other organic additives.

3.3. Catalytic Thiophene Oligomerization. To probe the effect of the physicochemical differences induced by the extrudate formulations on catalytic properties, a suitable acidcatalyzed reaction was selected. Previous work has shown that the oligomerization of thiophene is a probe reaction that can gain insight into how the nature and/or number of BASs (and also porosity), in zeolites and zeolite-shaped bodies, influence catalytic reactivity and intermediate/product selectivity. ${ }^{27-29,64-66}$ Given that a large majority of oligomer species produced during the acid-catalyzed reaction are lightabsorbing, they can be distinguished and followed in a timeresolved manner using in situ UV-vis absorption diffusereflectance spectroscopy. ${ }^{67,68}$ Figure 5a provides a general reaction scheme for the thiophene oligomerization reaction on a zeolite BAS, with the predominant intermediate and product species shown, and their respective absorption wavelengths (nm). Upon adsorption and protonation of the thiophene monomer, at least two reaction pathways are then undertaken: (i) oligomerization and (ii) ring-opening. Under the reaction conditions employed, it is likely that initial conversion of thiophene will take place on the external BAS, with the internal BAS also playing a significant role as thiophene monomers diffuse into the zeolite channels over time. Furthermore, the molecular dimensions of the oligomer species formed during the reaction are also an indication of which BAS are responsible, but can be related to the meso-/macropore dimensions of the extrudate under consideration.

Figure S8 reveals the time-resolved absorption spectra recorded during $\sim 15 \mathrm{~min}$ of reaction for each zeolite-based extrudate prepared with distinct formulations (Chart 1 ). It is clear that all zeolite-based extrudates produce a mixture of both thiol-like species (ring-opening pathway) and oligomer species (oligomerization pathway); however, there are distinct differences between the samples. Considering each extrudate sample contains the same weight ratio of the active zeolite component, and the fact that the additives used (or not) in each sample are primarily present to improve the mechanical strength of the extrudates, it is surprising to observe the extent of their impact on the catalytic performance.

Looking first at the species that can form on both external and internal zeolite BAS, for example, the thiophene dimer $(345 \mathrm{~nm})$ (Figure $5 \mathrm{~b})$, the ZSM-5 extrudate displays the highest rate of formation initially $(<200 \mathrm{~s})$, as compared to the composite extrudates. This is attributed to the high accessibility (high surface area and mesopore volume (Table 1)) of thiophene monomers to the high number of BAS available $\left(342 \mu \mathrm{mol} \mathrm{g}^{-1}\right)$ in the pure ZSM-5 extrudate, with the composite extrudates displaying a lower initial rate of formation due to initial limitations in mass transfer. However, either due to the sequential conversion of these dimers to larger oligomers, or due to the limitation in mass transfer of these larger species in the ZSM-5 extrudate (as compared to the composite extrudates that have macroporosity), the ZSM-5 extrudate displays the lowest overall absorbance for the thiophene dimer over the total reaction time. Considering EXT-5 and EXT-4 also have the high numbers of BAS (408 and $396 \mu \mathrm{mol} \mathrm{g}^{-1}$ ) but contrarily have high macroporosity and display the highest overall absorbance for this dimer species during the reaction (Figure 5a), it suggests that limitations in mass transport in the ZSM-5 extrudate are responsible for the lowest concentration of such species.

However, the trend is not only associated with the porosity characteristics of the samples, as there is indeed a correlation between the number of total BAS and the overall absorbance of the dimer species for the composite extrudates (with EXT-3 appearing to be an exception to this trend).

To observe the impact of the additives in relation to the zeolites external BAS and how they impact the catalytic performance, the formation of the pentamer thiopene oligomer $(645 \mathrm{~nm})$ was tracked during the reaction and is displayed in Figure 5c. Considering the large molecular dimensions of this oligomer, and its impossibility to fit inside ZSM-5 pores, it can be exclusively used as a direct means to study differences in external BAS between the samples. Similarly to the dimer species, the pure ZSM-5 extrudate has the highest initial rate of formation toward this species, due to the high initial accessibility of the external BAS sites. However, given the larger interparticle porosity and the close proximity of the $\mathrm{Al}_{2} \mathrm{O}_{3}$ binder to the zeolites in the composite extrudates, together with the larger meso- and macropore volume (Table $1)$, these properties allow for the transport and retention of a larger concentration of the thiophene pentamer (and larger oligomers $\lambda>655 \mathrm{~nm}){ }^{28}$ For the composite extrudates, there is indeed a direct trend in the number of external BAS and the absorbance of the $645 \mathrm{~nm}$ band (external BAS: EXT-5 = EXT4 > EXT-2, matching the top three extrudates with the highest absorbance to the pentamer).

Considering that the concentration of oligomers and the degree of oligomerization are directly related to the amount/ proximity of BAS for many oligomerization reactions, ${ }^{66,69}$ this is a clear proof-of-concept that, dependent on the additives used in the formulation, the product selectivity of a reaction can be tuned accordingly, and therefore the role of the 
additives should go beyond just enhancement in mechanical strength.

\section{CONCLUSIONS}

By systematically adding and combining commonly employed organic additives to formulations of zeolite-based catalyst bodies, together with their thorough physicochemical characterization on multiple length scales, we have revealed the significant impact they can have on the catalytic properties of these industrial-grade catalysts. In terms of chemical alterations, the addition of acidic peptizing agents, such as acetic acid, leads to the dealumination of the ZSM-5 crystals, and the creation of additional Brønsted acid sites via $\mathrm{Al}$ migration from the binder. Such binder effects were effectively hindered when lubricating agents were incorporated into the formulation, possibly due to their chelating properties, effectively scavenging Al species. Moreover, replacing acetic acid with nitric acid had a substantial impact on the amount of Brønsted and Lewis acid sites, with the latter reduced considerably due to leaching of EFAl. Upon combination with plasticizing agents, such as methylcellulose, the degree of zeolite dealumination increased significantly, most likely due to the decomposition products formed upon its breakdown during heat-treatment, effectively dealuminating the zeolite. Aside from their impact on catalytic acid sites, each organic additive significantly influenced the pore architecture of the catalyst bodies. Specifically, the choice of plasticizing and lubricating agents distinctly tailored the meso- and macroporosity of the final catalyst body, mainly due to the "skeleton" pore structure left behind upon the "burning off" of the organics upon heat-treatment. Collectively, each individually altered physical and chemical attribute has dramatic benefits and consequences for the catalytic performance of the materials (as shown by the acid-catalyzed thiophene oligomerization reaction). Given the industrial importance of these zeolite-based catalyst bodies, such fundamental insights can lead to enhanced formulations and design, such as tailoring BAS/LAS (key to optimum product selectivity), to achieve enhanced process efficiency.

\section{ASSOCIATED CONTENT}

\section{S Supporting Information}

The Supporting Information is available free of charge on the ACS Publications website at DOI: 10.1021/acscatal.9b00151.

Detailed experimental methods, characterization data, and catalytic testing data (PDF)

\section{AUTHOR INFORMATION}

\section{Corresponding Authors}

*E-mail: g.t.whiting@uu.nl.

*E-mail: b.m.weckhuysen@uu.nl.

\section{ORCID $\odot$}

Bert M. Weckhuysen: 0000-0001-5245-1426

\section{Notes}

The authors declare no competing financial interest.

\section{ACKNOWLEDGMENTS}

We thank Pasi Paalanen (Utrecht University, UU) for Ar physisorption and XRD measurements, as well as Serguei Matveev (UU) for assistance with SEM-EDX imaging. Furthermore, we thank Martijn van den Ende (UU), Nikolaos
Nikolopoulos (UU), and Dr. Andre Niemeijer (UU) for their help with the crush-strength measurements. We are also grateful to Philippe Bazin (ENSICAEN) for the technical support with the FT-IR spectroscopy measurements. The NMR studies were supported by a Middelgroot program (no. 700.58.102 to M.B.), and uNMR-NL, an NWO-funded National Roadmap Large-Scale Facility for The Netherlands (no. 184.032.207). This work was funded by a NWO Veni grant, awarded to G.T.W. (no. 722.015.003), and a NWO Gravitation program (The Netherlands Center for Multiscale Catalytic Energy Conversion (MCEC)) to B.M.W.

\section{REFERENCES}

(1) Corma, A. Inorganic Solid Acids and Their Use in AcidCatalyzed Hydrocarbon Reactions. Chem. Rev. 1995, 95, 559-614.

(2) Corma, A.; Díaz-Cabañas, M. J.; Martínez-Triguero, J.; Rey, F.; Rius, J. A Large-Cavity Zeolite with Wide Pore Windows and Potential as an Oil Refining Catalyst. Nature 2002, 418, 514-517.

(3) Climent, M. J.; Corma, A.; Iborra, S. Heterogeneous Catalysts for the One-Pot Synthesis of Chemicals and Fine Chemicals. Chem. Rev. 2011, 111, 1072-1133.

(4) Yarulina, I.; Chowdhury, A. D.; Meirer, F.; Weckhuysen, B. M.; Gascon, J. Recent Trends and Fundamental Insights in the Methanolto-Hydrocarbons Process. Nat. Catal. 2018, 1, 398-411.

(5) Young, L. B.; Butter, S. A.; Kaeding, W. W. Shape Selective Reactions with Zeolite Catalysts: III. Selectivity in Xylene Isomerization, Toluene-Methanol Alkylation, and Toluene Disproportionation over ZSM-5 Zeolite Catalysts. J. Catal. 1982, 76, 418-432.

(6) Tanabe, K.; Hölderich, W. F. Industrial Application of Solid Acid-base Catalysts. Appl. Catal., A 1999, 181, 399-434.

(7) Chen, N. Y.; Garwood, W. E. Industrial Application of ShapeSelective Catalysis. Catal. Rev.: Sci. Eng. 1986, 28, 185-264.

(8) Yilmaz, B.; Müller, U. Catalytic Applications of Zeolites in Chemical Industry. Top. Catal. 2009, 52, 888-895.

(9) Chowdhury, A. D.; Houben, K.; Whiting, G. T.; Chung, S.-H.; Baldus, M.; Weckhuysen, B. M. Electrophilic Aromatic Substitution over Zeolites Generates Wheland-Type Reaction Intermediates. Nat. Catal. 2018, 1, 23-31.

(10) Olsbye, U.; Svelle, S.; Lillerud, K. P.; Wei, Z. H.; Chen, Y. Y.; Li, J. F.; Wang, J. G.; Fan, W. B. The Formation and Degradation of Active Species during Methanol Conversion over Protonated Zeotype Catalysts. Chem. Soc. Rev. 2015, 44, 7155-7176.

(11) Karwacki, L.; Kox, M. H. F.; Matthijs De Winter, D. A.; Drury, M. R.; Meeldijk, J. D.; Stavitski, E.; Schmidt, W.; Mertens, M.; Cubillas, P.; John, N.; Chan, A.; Kahn, N.; Bare, S. R.; Anderson, M.; Kornatowski, J.; Weckhuysen, B. M. Morphology-Dependent Zeolite Intergrowth Structures Leading to Distinct Internal and Outer-Surface Molecular Diffusion Barriers. Nat. Mater. 2009, 8, 959-965.

(12) Olsbye, U.; Svelle, S.; BjØrgen, M.; Beato, P.; Janssens, T. V. W.; Joensen, F.; Bordiga, S.; Lillerud, K. P. Conversion of Methanol to Hydrocarbons: How Zeolite Cavity and Pore Size Controls Product Selectivity. Angew. Chem., Int. Ed. 2012, 51, 5810-5831.

(13) Jacobsen, C. J. H.; Madsen, C.; Houzvicka, J.; Schmidt, I.; Carlsson, A. Mesoporous Zeolite Single Crystals. J. Am. Chem. Soc. 2000, 122, 7116-7117.

(14) Perea, D. E.; Arslan, I.; Liu, J.; Ristanović, Z.; Kovarik, L.; Arey, B. W.; Lercher, J. A.; Bare, S. R.; Weckhuysen, B. M. Determining the Location and Nearest Neighbours of Aluminium in Zeolites with Atom Probe Tomography. Nat. Commun. 2015, 6, 7589.

(15) Jacobs, P. A.; Flanigen, E. M.; Jansen, J. C.; van Bekkum, H. Introduction to Zeolite Science and Practice; Elsevier: Amsterdam, 2001.

(16) Remans, T.; Jenzer, G.; Hoek, A. In Handbook of Heterogeneous Catalysis; Ertl, G., Knözinger, H., Schüth, F., Weitkamp, J., Eds.; Wiley-VCH: Germany, 2008.

(17) Mitchell, S.; Michels, N.-L.; Pérez-Ramírez, J. From Powder to Technical Body: The Undervalued Science of Catalyst Scale Up. Chem. Soc. Rev. 2013, 42, 6094-6112. 
(18) Vanderspurt, T. H.; Dienes, E. K.; Riley, R. E.; Tungate, F. L. Zeolite aggregates and catalysts. US5552035A, 1996.

(19) Ghosh, A. K.; Mihut, C.; Simmons, M. Method of Forming Zeolite Shaped Body with Silica Binder. US9180441B2, 2014.

(20) Lynn, M. Method of Making a High Strength Catalyst, Catalyst Support or Adsorber. US5633217A, 1994.

(21) Kaminsky, M. P.; Shawl, E. T.; Augustine, S. M. Inorganic Oxide Extrudates. US7825204B2, 2010.

(22) Akhtar, F.; Andersson, L.; Ogunwumi, S.; Hedin, N.; Bergström, L. Structuring Adsorbents and Catalysts by Processing of Porous Powders. J. Eur. Ceram. Soc. 2014, 34, 1643-1666.

(23) Tischer, R. E. Preparation of Bimodal Aluminas and Molybdena/Alumina Extrudates. J. Catal. 1981, 72, 255-265.

(24) Rhee, Y.-W.; Guin, J. A. Preparation of Alumina Catalyst Supports and $\mathrm{NiMo} / \mathrm{Al}_{2} \mathrm{O}_{3}$ Catalysts. Korean J. Chem. Eng. 1993, 10, $112-123$.

(25) Absi-Halabi, M.; Stanislaus, A.; Al-Zaid, H. Effect of Acidic and Basic Vapors on Pore Size Distribution of Alumina under Hydrothermal Conditions. Appl. Catal., A 1993, 101, 117-128.

(26) Hargreaves, J. S. J.; Munnoch, A. L. A Survey of the Influence of Binders in Zeolite Catalysis. Catal. Sci. Technol. 2013, 3, 1165-1171.

(27) Whiting, G. T.; Meirer, F.; Valencia, D.; Mertens, M. M.; Bons, A.-J.; Weiss, B. M.; Stevens, P. A.; De Smit, E.; Weckhuysen, B. M. Selective Staining of BrØnsted Acidity in Zeolite ZSM-5-Based Catalyst Extrudates Using Thiophene as a Probe. Phys. Chem. Chem. Phys. 2014, 16, 21531-21542.

(28) Whiting, G. T.; Meirer, F.; Mertens, M. M.; Bons, A. J.; Weiss, B. M.; Stevens, P. A.; De Smit, E.; Weckhuysen, B. M. Binder Effects in $\mathrm{SiO}_{2}$ and $\mathrm{Al}_{2} \mathrm{O}_{3}$-Bound Zeolite ZSM-5-Based Extrudates as Studied by Microspectroscopy. ChemCatChem 2015, 7, 1312-1321.

(29) Whiting, G. T.; Chowdhury, A. D.; Oord, R.; Paalanen, P.; Weckhuysen, B. M. The Curious Case of Zeolite-clay/Binder Interactions and Their Consequences for Catalyst Preparation. Faraday Discuss. 2016, 188, 369-386.

(30) Verkleij, S. P.; Whiting, G. T.; Esclapez, S. P.; Mertens, M. M.; Bons, A.-J.; Burgers, M.; Weckhuysen, B. M. Operando MicroSpectroscopy on ZSM-5 Containing Extrudates during the Oligomerization of 1-Hexene. Catal. Sci. Technol. 2018, 8, 2175-2185.

(31) Michels, N.-L.; Mitchell, S.; Pérez-Ramírez, J. Effects of Binders on the Performance of Shaped Hierarchical MFI Zeolites in Methanol-to-Hydrocarbons. ACS Catal. 2014, 4, 2409-2417.

(32) Zhang, Y.; Zhou, Y.; Qiu, A.; Wang, Y.; Xu, Y.; Wu, P. Effect of Alumina Binder on Catalytic Performance of PtSnNa/ZSM-5 Catalyst for Propane Dehydrogenation. Ind. Eng. Chem. Res. 2006, 45, 22132219.

(33) Choudhary, V. R.; Devadas, P.; Kinage, A. K.; Guisnet, M. Influence of Binder on the Acidity and Performance of $\mathrm{H}$-Gallosilicate (MFI) Zeolite in Propane Aromatization. Appl. Catal., A 1997, 162, 223-233.

(34) Fougerit, J. M.; Gnep, N. S.; Guisnet, M.; Amigues, P.; Duplan, J. L.; Hugues, F. Effect of the Binder on the Properties of a Mordenite Catalyst for the Selective Conversion of Methanol into Light Olefins. Stud. Surf. Sci. Catal. 1994, 84, 1723-1730.

(35) Martin, A.; Berndt, H.; Lohse, U.; Wolf, U. Effect of Si: Al Ratio and Type of Binder on the Catalytic Properties of HZSM-5 Catalysts. J. Chem. Soc., Faraday Trans. 1993, 89, 1277-1282.

(36) Lee, K.-Y.; Lee, H.-K.; Ihm, S.-K. Influence of Catalyst Binders on the Acidity and Catalytic Performance of HZSM-5 Zeolites for Methanol-to-Propylene (MTP) Process: Single and Binary Binder System. Top. Catal. 2010, 53, 247-253.

(37) Gola, A.; Rebours, B.; Milazzo, E.; Lynch, J.; Benazzi, E.; Lacombe, S.; Delevoye, L.; Fernandez, C. Effect of Leaching Agent in the Dealumination of Stabilized Y Zeolites. Microporous Mesoporous Mater. 2000, 40, 73-83.

(38) Yan, Z.; Ma, D.; Zhuang, J.; Liu, X.; Liu, X.; Han, X.; Bao, X.; Chang, F.; Xu, L.; Liu, Z. On the Acid-Dealumination of USY Zeolite: A Solid State NMR Investigation. J. Mol. Catal. A: Chem. 2003, 194, 153-167.
(39) Baran, R.; Millot, Y.; Onfroy, T.; Krafft, J.-M.; Dzwigaj, S. Influence of the Nitric Acid Treatment on Al Removal, Framework Composition and Acidity of BEA Zeolite Investigated by XRD, FTIR and NMR. Microporous Mesoporous Mater. 2012, 163, 122-130.

(40) Martin, A. J.; Mitchell, S.; Kunze, K.; Weston, K. C.; PérezRamírez, J. Visualising Compositional Heterogeneity during the Scale up of Multicomponent Zeolite Bodies. Mater. Horiz. 2017, 4, 857861.

(41) Mitchell, S.; Michels, N.-L.; Kunze, K.; Pérez-Ramírez, J. Visualization of Hierarchically Structured Zeolite Bodies from Macro to Nano Length Scales. Nat. Chem. 2012, 4, 825-831.

(42) Potter, M. Zeolite Aggregates and Catalysts. US5552035, 1994.

(43) Farnos, M. D.; Forbus, T. R.; McWilliams, J. P.; Shihabi, D. S. Catalytic Dewaxing over Silica Bound Molecular Sieve. US5614079, 1994.

(44) Brendan, M. D. Process for Isomerizing Linear Olefins to Isoolefins. US5510306, 1993.

(45) Absil, R. P. L.; Angevine, P. J.; Herbst, J. A.; Klocke, D. J.; McWilliams, J. P.; Han, S.; Shihabi, D. S. Method of Preparing a Zeolite Catalyst Bound with a Refractory Oxide of Low Acidity. US5053374, 1991.

(46) Uphade, B. S.; Gopal, S. Zeolite-Binder Catalyst Composition. US8252710B2, 2010.

(47) Emeis, C. A. Determination of Integrated Molar Extinction Coefficients for Infrared Absorption Bands of Pyridine Adsorbed on Solid Acid Catalysts. J. Catal. 1993, 141, 347-354.

(48) Nesterenko, N. S.; Thibault-Starzyk, F.; Montouillout, V.; Yuschenko, V. V.; Fernandez, C.; Gilson, J.-P.; Fajula, F.; Ivanova, I. I. Accessibility of the Acid Sites in Dealuminated Small-Port Mordenites Studied by FTIR of Co-Adsorbed Alkylpyridines and CO. Microporous Mesoporous Mater. 2004, 71, 157-166.

(49) Mlekodaj, K.; Tarach, K.; Datka, J.; Góra-Marek, K.; Makowski, W. Porosity and Accessibility of Acid Sites in Desilicated ZSM-5 Zeolites Studied Using Adsorption of Probe Molecules. Microporous Mesoporous Mater. 2014, 183, 54-61.

(50) Fyfe, C. A.; Gobbi, G. C.; Kennedy, G. J.; Graham, J. D.; Ozubko, R. S.; Murphy, W. J.; Bothner-By, A.; Dadok, J.; Chesnick, A. S. Detailed Interpretation of the ${ }^{29} \mathrm{Si}$ and ${ }^{27} \mathrm{Al}$ High-Field MAS n.m.r. Spectra of Zeolites Offretite and Omega. Zeolites 1985, 5, 179-183.

(51) Jirátová, K.; Janáček, L.; Schneider, P. Influence Of Aluminium Hydroxide Peptization On Physical Properties Of Alumina Extrudates. Stud. Surf. Sci. Catal. 1983, 16, 653-663.

(52) Zheng, Y.; Song, J.; Xu, X.; He, M.; Wang, Q.; Yan, L. Peptization Mechanism of Boehmite and Its Effect on the Preparation of a Fluid Catalytic Cracking Catalyst. Ind. Eng. Chem. Res. 2014, 53, 10029-10034.

(53) Whiting, G. T.; Nikolopoulos, N.; Nikolopoulos, I.; Chowdhury, A. D.; Weckhuysen, B. M. Visualizing Pore Architecture and Molecular Transport Boundaries in Catalyst Bodies with Fluorescent Nanoprobes. Nat. Chem. 2019, 11, 23-31.

(54) Wang, Q. L.; Giannetto, G.; Guisnet, M. Dealumination of Zeolites III. Effect of Extra-Framework Aluminum Species on the Activity, Selectivity, and Stability of Y Zeolites in n-Heptane Cracking. J. Catal. 1991, 130, 471-482.

(55) Li, S.; Huang, S.-J.; Shen, W.; Zhang, H.; Fang, H.; Zheng, A.; Liu, S.-B.; Deng, F. Probing the Spatial Proximities among Acid Sites in Dealuminated H-Y Zeolite by Solid-State NMR Spectroscopy. J. Phys. Chem. C 2008, 112, 14486-14494.

(56) Xin, H.; Li, X.; Fang, Y.; Yi, X.; Hu, W.; Chu, Y.; Zhang, F.; Zheng, A.; Zhang, H.; Li, X. Catalytic Dehydration of Ethanol over Post-Treated ZSM-5 Zeolites. J. Catal. 2014, 312, 204-215.

(57) Corma, A.; Grande, M.; Fornés, V.; Cartlidge, S.; Shatlock, M. P. Interaction of Zeolite Alumina with Matrix Silica in Catalytic Cracking Catalysts. Appl. Catal. 1990, 66, 45-57.

(58) Gelin, P.; Gueguen, C. Hydrothermal Modifications of MatrixEmbedded Y-Faujasite and Offretite Zeolites. Appl. Catal. 1988, 38, 225-233.

(59) Chang, C. D.; Hellring, S. D.; Miale, J. N.; Schmitt, K. D.; Brigandi, P. W.; Wu, E. L. Insertion of Aluminium into High-Silica- 
Content Zeolite Frameworks. Part 3.-Hydrothermal Transfer of Aluminium from $\mathrm{Al}_{2} \mathrm{O}_{3}$ into [Al]ZSM-5 and [B]ZSM-5. J. Chem. Soc., Faraday Trans. 1 1985, 81, 2215-2224.

(60) Martin, A.; Berndt, H.; Lohse, U.; Wolf, U. Effect of Si:Al Ratio and Type of Binder on the Catalytic Properties of HZSM-5 Catalysts. J. Chem. Soc., Faraday Trans. 1993, 89, 1277-1282.

(61) Shen, D. K.; Gu, S. The Mechanism for Thermal Decomposition of Cellulose and Its Main Products. Bioresour. Technol. 2009, 100, 6496-6504.

(62) Giudici, R.; Kouwenhoven, H.; Prins, R. Comparison of Nitric and Oxalic Acid in the Dealumination of Mordenite. Appl. Catal., A 2000, 203, 101-110.

(63) Idris, A.; Mat Zain, N.; Noordin, M. Y. Synthesis, Characterization and Performance of Asymmetric Polyethersulfone (PES) Ultrafiltration Membranes with Polyethylene Glycol of Different Molecular Weights as Additives. Desalination 2007, 207, 324-339.

(64) Kox, M. H. F.; Mijovilovich, A.; Sättler, J. J. H. B.; Stavitski, E.; Weckhuysen, B. M. The Catalytic Conversion of Thiophenes over Large H-ZSM-5 Crystals: An X-Ray, UV/Vis, and Fluorescence Microspectroscopic Study. ChemCatChem 2010, 2, 564-571.

(65) Buurmans, I. L. C.; Ruiz-Martínez, J.; Knowles, W. V.; van der Beek, D.; Bergwerff, J. A.; Vogt, E. T. C.; Weckhuysen, B. M. Catalytic Activity in Individual Cracking Catalyst Particles Imaged throughout Different Life Stages by Selective Staining. Nat. Chem. 2011, 3, 862867.

(66) Ruiz-Martínez, J.; Buurmans, I. L. C.; Knowles, W. V.; van der Beek, D.; Bergwerff, J. A.; Vogt, E. T. C.; Weckhuysen, B. M. Microspectroscopic Insight into the Deactivation Process of Individual Cracking Catalyst Particles with Basic Sulfur Components. Appl. Catal., A 2012, 419-420, 84-94.

(67) Geobaldo, F.; Palomino, T.; Bordiga, S.; Fisica, C.; Giuria, V. Pietro. Phys. Chem. Chem. Phys. 1999, 1, 561-569.

(68) Valencia, D.; Whiting, G. T.; Bulo, R. E.; Weckhuysen, B. M. Protonated Thiophene-Based Oligomers as Formed within Zeolites: Understanding Their Electron Delocalization and Aromaticity. Phys. Chem. Chem. Phys. 2016, 18, 2080-2086.

(69) Mlinar, A. N.; Zimmerman, P. M.; Celik, F. E.; Head-Gordon, M.; Bell, A. T. Effects of Brønsted-Acid Site Proximity on the Oligomerization of Propene in H-MFI. J. Catal. 2012, 288, 65-73. 